\title{
GAMBARAN PEMUTAKHIRAN DATA KELUARGA MISKIN (GAKIN) KOTA SURABAYA
}

\author{
DESCRIPTION OF UPDATED DATA OF POOR FAMILY (GAKIN) IN SURABAYA CITY
}

\author{
Diky Novariyanto \\ Fakultas Kesehatan Masyarakat, Universitas Airlangga \\ J1. Mulyorejo Kampus C Unair, Surabaya 60115 \\ Alamat Korespondensi: \\ E-mail: Ronaldikin88@gmail.com
}

\begin{abstract}
Surabaya City Government implemented a policy of assistance for poor families. The data beneficiary poor families need to be updated every two years. The activity is called Gakin data updating. Updating data-Gakin is comprised of a series of family data collection activities using a predetermined list of questions and process the data to obtain the status of family poverty. Interest Data Updates Gakin is giving in order to determine the effectiveness of the target. Parties in charge of handling data updates Gakin is the field of Community Development of Population Control Office of Women's Empowerment and Child Protection Surabaya through DDKM. DDKM activities initiated by promoting the activities DDKM, filling the questionnaire and verification stages. Based on data updates Gakin in 2008, 2010 and 2012 contained in the effectiveness of policy implementation.
\end{abstract}

Keywords: Descriptive, Data poor families, Surabaya 


\section{ABSTRAK}

Pemerintah Kota Surabaya menerapkan kebijakan pemberian bantuan bagi keluarga miskin. Data-data penerima bantuan keluarga miskin perlu diperbarui setiap dua tahun sekali. Kegiatan tersebut dinamakan pemutakhiran data Gakin. Pemutakhiran data Gakin tersebut terdiri-dari serangkaian kegiatan pengumpulan data keluarga dengan menggunakan daftar pertanyaan yang sudah ditentukan dan mengolah data untuk memperoleh status kemiskinan keluarga. Tujuan Pemutakhiran Data Gakin adalah memberikan efektivitas dalam rangka penentuan sasaran. Pihak yang bertugas dalam menangani pemutakhiran data Gakin adalah bidang Pemberdayaan Masyarakat dari Dinas Pengendalian Penduduk Pemberdayaan Perempuan dan Perlindungan Anak Kota Surabaya melalui kegiatan DDKM. Kegiatan DDKM diawali oleh sosialisasi kegiatan DDKM, pengisian kuisioner dan verifikasi berjenjang. Berdasarkan data pemutakhiran Gakin tahun 2008, 2010 dan 2012 terdapat efektifitas dalam penerapan kebijakan.

\section{Kata Kunci: Gambaran, Data Gakin, Surabaya}

\section{PENDAHULUAN}

Kesenjangan kesejahteraan penduduk dapat diatasi oleh adanya bantuan langsung maupun tidak langsung dari aspek kesehatan, pendidikan dan lain sebagainya. Untuk mendapatkan bantuan tersebut perlu adanya sistim verifikasi dan validasi data. Sistim verifikasi dan validasi data bantuan kesenjangan kesejahteraan masyarakat di Bapemas dan KB (sekarang berubah menjadi Dinas Pengendalian Penduduk Pemberdayaan Perempuan dan Perlindungan Anak) Kota Surabaya ditangani oleh bidang pemberdayaan masyarakat (PM), melalui program keluarga miskin (Gakin). Dalam penentuan penerima bantuan program Gakin perlu adanya sistim verifikasi yang dinamakan pemutakhiran data Gakin.

Kegiatan pemutakhiran data Gakin melalui beberapa serangkaian proses. Salah satu kegiatan penunjangnya adalah kegiatan DDKM (Dinamisasi Data Keluarga Miskin). Dalam kegiatan DDKM, Dinas Pengendalian Penduduk Pemberdayaan Perempuan dan Perlindungan Anak Kota Surabaya dibantu oleh pihak konsultan. Ada beberapa tahapan di dalam kegiatan DDKM tersebut yang perlu untuk dikaji.

Tahapan-tahapan yang perlu dikaji tersebut adalah mengidentifikasi setiap tahapan dalam proses pemutakhiran data Gakin, mengidentifikasi keseluruhan proses pemutakhiran data Gakin dan mengidentifikasi pemutakhiran data Gakin pada tahun-tahun sebelumnya.

Manfaat yang akan diperoleh berdasarkan alur/gambaran proses pemutakhiran data Gakin tersebut adalah penulis lebih paham tentang alur proses pemutakhiran data Gakin Kota Surabaya. Diharapkan dengan adanya pemutakhiran data Gakin akan berdampak pada efektivitas dari pemberian bantuan pada keluarga miskin (Gakin).

\section{METODE PENELITIAN}

Berdasarkan waktu, kajian ilmiah ini termasuk dalam kategori retrospektif yang menggambarkan data-data pada tahun sebelumnya guna mengetahui informasi alur proses pemutakhiran data Gakin di Kota Surabaya. Subjek dalam kajian ilmiah ini adalah cakupan keluarga miskin di Kota Surabaya.

Kajian ilmiah ini dilakukan di Dinas Pengendalian Penduduk Pemberdayaan Perempuan dan Perlindungan Anak (Bapemas dan KB) Kota Surabaya pada bulan Agustus - September 2016. Sumber data adalah skematika kegiatan pemutakhiran data Gakin dan pelaporan kegiatan pada tiga tahun terakhir (2008, 2010 dan 2012).

Analisis data menggunakan dekriptif untuk memberikan gambaran alur proses pemutakhiran data Gakiin di Kota 
Surabaya. Alur proses pemutakhiran data Gakin yang telah terbentuk dinarasikan dan mengkaji data Gakin tahun 2008, 2010 dan 2012. Penjabaran tentang alur proses pemutakhiran data Gakin akan memberikan informasi secara menyeluruh tentang gambaran kebijakan pemberian bantuan Gakin di Kota Surabaya.

\section{HASIL \& PEMBAHASAN}

Berdasarkan Peraturan Presiden No. 15 tahun 2010 tentang percepatan penanggulangan kemiskinan menyatakan bahwa dalam upaya percepatan penanggulangan kemiskinan diperlukan langkah-langkah koordinasi secara terpadu lintas pelaku dalam penyiapan, perumusan dan penyelenggaraan kebijakan penanggulangan kemiskinan. Dalam percepatan penanggulangan kemiskinan tersebut perlu di kaji ulang dalam pemberian bantuan Gakin. Kegiatan pemutakhiran data Gakin dapat mengurangi risiko salah sasaran dalam pemberian dana bantuan. Pemutakhiran data Gakin di Kota Surabaya dilakukan selama dua tahun sekali (Mantra, 2009).

Contoh kegiatan pemberian bantuan Gakin adalah pembagian beras miskin (Raskin), pelayanan kesehatan melalui (Jamkesmas, Jamkesda dan BPJS KIS) dan PMDP jalur Gakin. Pemutakhiran data Gakin dilakukan melalui kegiatan DDKM (Dinamisasi Data Keluarga Miskin). DDKM merupakan suatu kegiatan yang bertujuan untuk menyaring sasaran yang akan diberikan intervensi program Gakin (Suharja, 2013).

Proses pemutakhiran data Gakin terdiri dari beberapa proses, yaitu: pemutakhiran data Gakin diawali dengan tahapan sosialiasi kegiatan DDKM (Dinamisasi Data Keluarga Miskin) kepada tenaga trainer yang dilakukan oleh Dinas Pengendalian Penduduk, Pemberdayaan Perempuan dan Perlindungan Anak Kota Surabaya. Pelatihan yang diberikan trainer kepada petugas pendata tersebut meliputi tata cara dalam pengisian kuisioner, penentuan sasaran dan teknik wawancara. Kemudian petugas pendata tingkat RT melakukan pendataan dengan menggunakan data Gakin tahun 2012 sebagai data sekunder acuannya.

Data usulan yang telah terkumpul dari masyarakat, kemudian diverifikasi melalui musyawarah disertai dengan berita acara, rekapitulasi dan tanda tangan pemangku setempat. Tahapan ini terjadi pada tingkat RT, RW, LKMK dan kelurahan. Data yang terkumpul di tingkat kelurahan, kemudian dientry ke simgakin.surabaya.go.id oleh pihak kelurahan. Data yang selesai dientry, tahapan berlanjut dengan verifikasi, validasi dan tanda tangan dari pemangku di tingkat kelurahan (Kasie kesra) dan lurah. Kemudian data-data tersebut dikirim ke kecamatan guna verifikasi, validasi dan tanda tangan dari pihak kecamatan. Dari kecamatan data berlanjut ke Dinas Pengendalian Penduduk, Pemberdayaan Perempuan dan Perlindungan Anak Kota Surabaya guna verifikasi, validasi dan tanda tangan tahap akhir. Berikut merupakan contoh data Gakin:

Tabel 1.1 Data Gakin Kota Surabaya Tahun 2008, 2010 dan 2012

\begin{tabular}{clccc}
\hline NO & KECAMATAN & KK 2008 & KK 2010 & KK 2012 \\
\hline 1 & ASEMROWO & 1848 & 1835 & 2053 \\
\hline 2 & BENOWO & 1463 & 1439 & 1726 \\
\hline 3 & BUBUTAN & 5320 & 5255 & 4352 \\
\hline 4 & BULAK & 1697 & 1689 & 1391 \\
\hline 5 & DUKUH PAKIS & 1436 & 1417 & 1510 \\
\hline 6 & GAYUNGAN & 804 & 784 & 1000 \\
\hline 7 & GENTENG & 2360 & 2325 & 2009 \\
\hline 8 & GUBENG & 5418 & 5301 & 5865 \\
\hline 9 & GUNUNG ANYAR & 1405 & 1386 & 1261 \\
\hline 10 & JAMBANGAN & 1529 & 1498 & 1596 \\
\hline 11 & KARANG PILANG & 1855 & 1827 & 1701 \\
\hline 12 & KENJERAN & 5329 & 5290 & 5047 \\
\hline 13 & KREMBANGAN & 5166 & 5099 & 4829 \\
\hline 14 & LAKAR SANTRI & 1976 & 1969 & 1968 \\
\hline 15 & MULYOREJO & 2118 & 2083 & 1744 \\
\hline 16 & PABEAN CANTIAN & 3680 & 3650 & 3281 \\
\hline 17 & PAKAL & 1240 & 1228 & 1331 \\
\hline 18 & RUNGKUT & 3383 & 3321 & 2275 \\
\hline 19 & SAMBI KEREP & 2129 & 2105 & 1181 \\
\hline 20 & SAWAHAN & 8814 & 8672 & 6780 \\
\hline 21 & SEMAMPIR & 10875 & 10787 & 10664 \\
\hline 22 & SIMOKERTO & 7776 & 7716 & 5793 \\
\hline 23 & SUKO MANUNGGAL & 1615 & 2829 & 2550 \\
\hline 24 & SUKOLILO & 4082 & 2804 & 2287 \\
\hline 25 & TAMBAK SARI & 9860 & 9804 & 9889 \\
\hline 26 & TANDES & 3181 & 3137 & 2507 \\
\hline 27 & TEGALSARI & 4247 & 4213 & 3752 \\
\hline 28 & TENGGILIS MEJOYO & 1189 & 1175 & 886 \\
\hline 29 & WIYUNG & 2597 & 2579 & 1830 \\
\hline 30 & WONOCOLO & 2685 & 2660 & 2402 \\
\hline 31 & WONOKROMO & 6670 & 6588 & 5242 \\
\hline & T O T A L & 113.747 & 112.465 & 100.702 \\
\hline
\end{tabular}




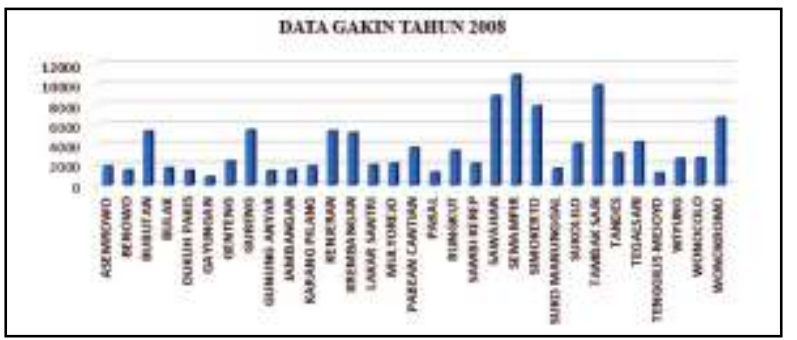

Gambar 1.1 Data Gakin Tahun 2008

Pada tahun 2008 jumlah data Gakin keseluruhan adalah 113.747 kk. Kecamatan yang memiliki jumlah data Gakin tertinggi adalah kecamatan Semampir dengan besaran $10.875 \mathrm{kk}$, sedangkan kecamatan yang memiliki jumlah data Gakin terendah adalah kecamatan Gayungan dengan besaran $804 \mathrm{kk}$.

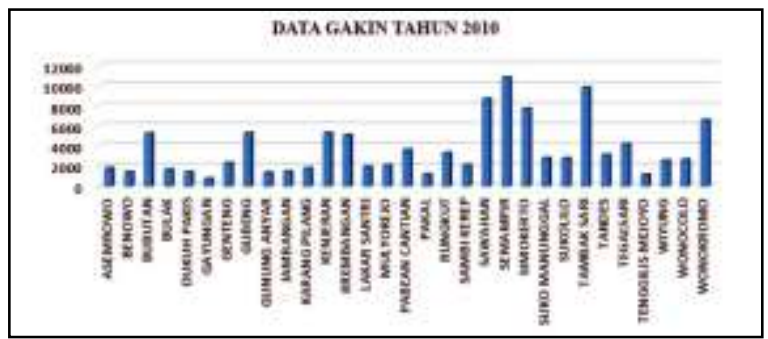

Gambar 1.2 Data Gakin Tahun 2010

Pada tahun 2010 jumlah data Gakin keseluruhan adalah $112.465 \mathrm{kk}$. Kecamatan yang memiliki jumlah data Gakin tertinggi adalah kecamatan Semampir dengan besaran $10.787 \mathrm{kk}$, sedangkan kecamatan yang memiliki jumlah data Gakin terendah adalah kecamatan Gayungan dengan besaran $784 \mathrm{kk}$.

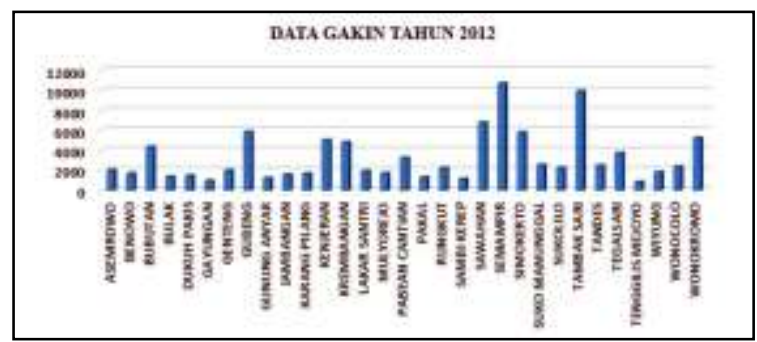

Gambar 1.3 Data Gakin Tahun 2012

Pada tahun 2012 jumlah data Gakin keseluruhan adalah 100.702 kk. Kecamatan yang memiliki jumlah data Gakin tertinggi adalah kecamatan Semampir dengan besaran $10.664 \mathrm{kk}$, sedangkan kecamatan yang memiliki jumlah data Gakin terendah adalah kecamatan Tenggilis Mejoyo dengan besaran $886 \mathrm{kk}$ (BAPEMAS \& KB Kota Surabaya, 2014).

\section{PEMBAHASAN}

Proses pemutakhiran data Gakin diharapkan dapat memberikan efektivitas dalam rangka penentuan sasaran. Pemutakhiran data Gakin dilakukan melalui kegiatan DDKM (Dinamisasi Data Keluarga Miskin). DDKM merupakan suatu kegiatan yang bertujuan untuk menyaring sasaran yang akan diberikan intervensi program Gakin.

Intervensi yang dihasilkan dari proses pemutakhiran data Gakin adalah program pembagian beras miskin (Raskin); pelayanan kesehatan (Jamkesmas, Jamkesda dan BPJS KIS); Program Minat dan Prestasi jalur keluarga miskin (PMDP). Diharapkan ketiga intervensi tersebut dapat berjalan secara efektif dalam percepatan penanggulanan kemiskinan khususnya di Kota Surabaya (BPS, 2013).

Proses pemutakhiran data Gakin diawali dengan tahap sosialisasi kegiatan DDKM yang dilakukan oleh pihak Dinas Pengendalian Penduduk, Pemberdayaan Perempuan dan Perlindungan Anak Kota Surabaya. Sosialisasi ini menjelaskan tentang gambaran umum kegiatan DDKM, dengan sasaran sosialisasi adalah tenaga trainer. Trainer tersebut akan memberikan pelatihan kepada petugas pendata kegiatan DDKM.

Pada tingkat bawah petugas kegiatan DDKM bekerja mencari usulan sasaran penerima bantuan dari masyarakat. Data usulan tersebut dibandingkan dengan data tahun 2012 sebagai pembandingnya. Setelah itu secara berjenjang data usulan tersebut diverifikasi pada tingkat kelurahan, kecamatan dan Dinas Pengendalian Penduduk, Pemberdayaan Perempuan dan Perlindungan Anak Kota Surabaya sebelum data tersebut diterima oleh walikota Surabaya (Arsyad, 2001).

Di beberapa kelurahan di Surabaya ada yang memiliki cakupan keluarga miskin terendah dikarenakan keberhasilan efektifitas dana bantuan dan semakin baik perekonomian warga setempat. Hal tersebut didukung oleh semakin bertambahnya lapangan pekerjaan diwilayah tersebut. Sedangkan kelurahan yang masih memiliki 
cakupan keluarga miskin tertinggi dikarenakan lapangan pekerjaan yang sempit diwilayah tersebut, masih banyak tindak kriminal diwilayah tersebut dan banyak ditemukan pemukiman kumuh. Secara garis besar dari tahun 2008 sampai 2012 data keluarga miskin (Gakin) mengalami penurunan, akan tetapi kegiatan pemutakhiran data Gakin ini perlu dilanjutkan guna memaksimalkan penentuan sasaran penerima bantuan Gakin.

\section{SARAN}

Penentuan sasaran penerima bantuan perlu dikaji ulang guna memperoleh efektifitas penerapan kebijakan. Selain itu perlu adanya sistim yang jelas tentang alur dari pemutakhiran data Gakin, karena saat ini, terkadang ada beberapa salah persepsi tentang kepengurusan pengajuan penerima dana bantuan.

Pemutakhiran data Gakin ini diharapkan dapat berlangsung secara berkesinambungan untuk memperoleh hasil yang maksimal guna mengentaskan masalah kemiskinan di Kota Surabaya. Selain itu harus ada peran serta pihak Dinas Pengendalian Penduduk, Pemberdayaan Perempuan dan Perlindungan Anak Kota Surabaya guna mengawasi proses usulan penerima dana bantuan di tingkat yang lebih rendah.

\section{DAFTAR PUSTAKA}

BPS. 2013. Lapaoran Pendahuluan Survei Demografi dan Kesehatan Indonesia 2012. Jakarta : BPS

BKKBN, 2014. Tata Cara Pelaksanaan Pencatatan Dan Pelaporan Pelayanan Kontrasepsi Program Kependudukan, Keluarga Berencana dan Pembangunan Keluarga Nasional. Jakarta

BAPEMAS \& KB Kota Surabaya, 2014. Profil BAPEMAS \& KB Kota Surabaya. Surabaya.

Mantra, Ida Bagus. 2009. Demografi Umum. Jakarta : Pustaka Pelajar.

Arsyad, L. 2001. Peramalan Bisnis. Edisi I. BPFE, yogyakarta.
Suharjo, B. 2013. Statistika Terapan. Graha Ilmu, Yogyakarta. 
JURNAL ILMIAH KESEHATAN MEDIAHUSADA | VOLUME 07/NOMOR 01/MARET 2018 